\title{
Homozygous variegate porphyria: an evolving clinical syndrome
}

\author{
R.J. Hift, P.N. Meissner, G. Todd' ${ }^{1}$ P. Kirby², D. Bilsland ${ }^{3}$, P. Collins ${ }^{3}$, \\ J. Ferguson ${ }^{3}$ and M.R. Moore ${ }^{4}$
}

MRC/UCT Liver Research Centre, Departments of Medicine and ${ }^{1}$ Dermatology, University of Cape Town, Observatory and ${ }^{2}$ Department of Anatomical Pathology, University of Stellenbosch, Tygerberg, South Africa, ${ }^{3}$ Photobiology Unit, Ninewells Hospital, Dundee, and ${ }^{4}$ Porphyrias Service, University of Glasgow, UK

Summary: Variegate porphyria is one of the most frequently encountered genetic conditions in South Africa. It is inherited as an autosomal dominant disease and in excess of $\mathbf{3 0 0}$ heterozygous cases have been studied by the Cape Town unit. Despite this, the homozygous condition has not previously been encountered in South Africa. We report two cases of homozygous variegate porphyria, one of whom represents the first South African case. We delineate a syndrome principally characterized by growth retardation, developmental delay, epileptic seizures, photosensitivity and an abnormal porphyrin excretion pattern. In addition we describe, in one case, two features not previously reported: skin disease in areas unexposed to light and a severe sensory neuropathy which may account at least in part for the hand deformities of this disorder.

\section{Introduction}

Variegate porphyria (VP) is the clinical syndrome resulting from deficient activity of the enzyme protoporphyrinogen oxidase (PPO) $)^{1,2}$ and is inherited as an autosomal dominant trait. In the heterozygous state, the clinical manifestations include neurovisceral crises or 'acute attacks' and skin disease. The cutaneous disease presents with photosensitivity which may result in blistering, erosions, a fragile skin with chronic scarring and pigmentary changes. ${ }^{3}$ The principal biochemical findings are of an increased excretion of protoporphyrin, coproporphyrin and pentacarboxylic porphyrin in the faeces. Increased porphyrins may also be detected in plasma and urine. However, asymptomatic carriers are believed to be common, and may or may not show abnormalities of porphyrin production. The condition is unusually prevalent in South Africa, where it is one of the most frequently encountered genetic conditions. The gene frequency amongst the white Afrikaner population of South Africa has been estimated at $0.3 \% .{ }^{4}$ This is ascribed to a founder effect; affected families having been traced back to a common ancestor who married at the Cape in 1688.

It is remarkable that no South African case of

Correspondence: R.J. Hift, F.C.P. (SA), MRC/UCT Liver Research Centre, Department of Medicine, University of Cape Town, Observatory 7925, South Africa.

Accepted: 17 May 1993 homozygous variegate porphyria (HVP) has yet been described despite the frequency of this gene, whereas a handful of cases have been identified elsewhere. ${ }^{5-10} \mathrm{We}$ describe here two further cases; one of whom represents the first South African case of HVP. A comparison of our cases with those previously described has allowed us to delineate a remarkably consistent syndrome; however, we describe an additional feature, a severe sensory neuropathy, which may account for some of the mutilating features of this disease.

\section{Case reports}

Case 1

A female child of Afrikaner origin with a normal 46XX karyotype, born to non-consanguineous parents, developed severe blistering of the face and hands within days of birth. A diagnosis of porphyria was confirmed in our laboratory at 9 months. Her biochemical profile, assessed by thin-layer chromatography and fluoroscanning, is . characteristic of VP (Table I). In addition, she showed an elevated erythrocyte protoporphyrin. The child's mother demonstrated the faecal porphyrin excretion pattern of VP, whereas the father had a normal profile. Both were asymptomatic. Two younger siblings were normal. An assay of PPO activity in Epstein-Barr virus-transformed 
Table I Porphyrin concentrations of proband and parents (Case 1) and proband (Case 2)

\begin{tabular}{|c|c|c|c|c|c|}
\hline & Proband 1 & Mother & Father & Proband 2 & $\begin{array}{l}\text { Reference } \\
\text { range/units }\end{array}$ \\
\hline Urine & & & & & \\
\hline Uroporphyrin & 3.1 & 1.0 & 0.6 & 144.4 & $\begin{array}{l}<20 \mathrm{nmol} / 10 \mathrm{mmol} \\
\text { creatinine }\end{array}$ \\
\hline Coproporphyrin & 10.1 & 33.9 & 6.8 & 87.1 & $\begin{array}{l}<240 \mathrm{nmol} / 10 \mathrm{mmol} \\
\text { creatinine }\end{array}$ \\
\hline \multicolumn{6}{|l|}{ Stool } \\
\hline Uroporphyrin & 5.3 & 0 & 0.7 & & $<1.7 \mathrm{nmol} / \mathrm{g}$ \\
\hline Pseudopentacarboxylic & 61.7 & 59.8 & 0.4 & & 0 \\
\hline Pentacarboxylic & 13.1 & 16.9 & 0.4 & & 0 \\
\hline Coproporphyrin & 67.3 & 131.0 & 8.9 & 449.0 & $<50 \mathrm{nmol} / \mathrm{g}$ \\
\hline Protoporphyrin & 698.0 & $1,020.0$ & 174.0 & 553.0 & $<200 \mathrm{nmol} / \mathrm{g}$ \\
\hline \multicolumn{6}{|l|}{ Plasma } \\
\hline Uroporphyrin & 1.5 & 0.7 & 0.2 & & $<2.5 \mathrm{nmol} / 1$ \\
\hline Coproporphryrin & 25.8 & 1.4 & 1.0 & & $<4.5 \mathrm{nmol} / 1$ \\
\hline Protoporphyrin & 45.6 & 7.5 & 0.0 & & 0 \\
\hline Erythrocyte & 4,400 & 1,301 & 8,855 & 7,894 & $<800 \mathrm{nmol} / 1$ \\
\hline
\end{tabular}

lymphoblasts showed no detectable activity in the proband; $50 \%$ of the activity of control lymphoblasts in the mother and $70 \%$ in the father (normal range $\mathrm{PPO}_{\mathrm{vmax}}=0.62-1.02 \mathrm{nmol}$ protoporphyrin/ $\mathrm{mg}$ protein/hour).

The child is now 6 years old. She has never developed symptoms of the acute porphyric attack. She has markedly foreshortened, stubby fingers and toes, resulting in severe functional impairment such that she cannot grasp a pencil or use a pair of scissors (Figure 1). Radiographs demonstrate brachydactyly with broad, short metacarpals and phalanges, and a delayed bone age (Figure 2).

She has severe skin disease, manifested by blistering, erosions, crusting, pigmentation and milia. The lesions have a wider distribution than those of heterozygous VP. In addition to typical blistering and scarring of sun-exposed areas, the skin in non-exposed areas of the arms, legs and trunk is thickened and infiltrated, and clearly abnormal. Histological abnormalities were demonstrated in biopsies taken from both sun-exposed (wrist) and unexposed (buttock) skin. Both showed features of porphyria: striking perivascular PASpositive non-fluorescent hyalin deposits were present in the papillary and upper reticular dermis of exposed skin. Similar but less marked changes were present around papillary dermal vessels of unexposed skin. In addition, exposed skin showed features of acute or chronic photodamage; basketweave hyperkeratosis, epidermal atrophy with necrotic keratinocytes, and marked dermal solar elasatosis. This was not present in unexposed skin.

She has severe myopia and a pendular nystagmus. Neurological development is delayed. Her perceptual and motor development are about one year behind the expected stage of development. 0 Verbal skills are appropriate for age and she appears to be of normal intelligence. Since the ageof 3 she has suffered infrequent complex partile seizures; an electroencephalogram was, howevg్,; normal. Over the past 2 years she has developecto gross sensory neuropathy of the hands and feet, manifesting with painless trauma to the hands. Electrophysiological studies of nerve conduction。 have demonstrated a reduced amplitude of conduc- $-\stackrel{\square}{\varrho}$ tion in the right and left median sensory nerves in $\overrightarrow{\vec{O}}$ keeping with a sensory neuropathy. No motor 3 abnormalities were demonstrable. Sural nerve conduction studies were normal, yet abnormalitieso were shown on histological examination of a suralo nerve biopsy specimen. Light and electron micro-3. scopic examination of the teased fibre preparation: revealed a paucity of small unmyelinated and: myelinated fibres. Wallerian degeneration waso present, but most noticeable was remarkable $₹$ widening of the nodal gaps and loss of Schwann cello cytoplasm over the gap. These features are in keeping with early segmental demyelination.

Treatment has been unrewarding. Anti- N convulsants have been withheld because of their porphyrinogenic potential. The skin disease re- ${ }_{0}^{\circ}$ mains severe despite avoidance of light and trials of $\mathrm{f}_{\mathrm{N}}$ sunblockers, oral-activated charcoal and betao carotene.

Case 2

A male infant, born to consanguineous parents, $\frac{0}{0}$ developed epilepsy at 5 months and showed 


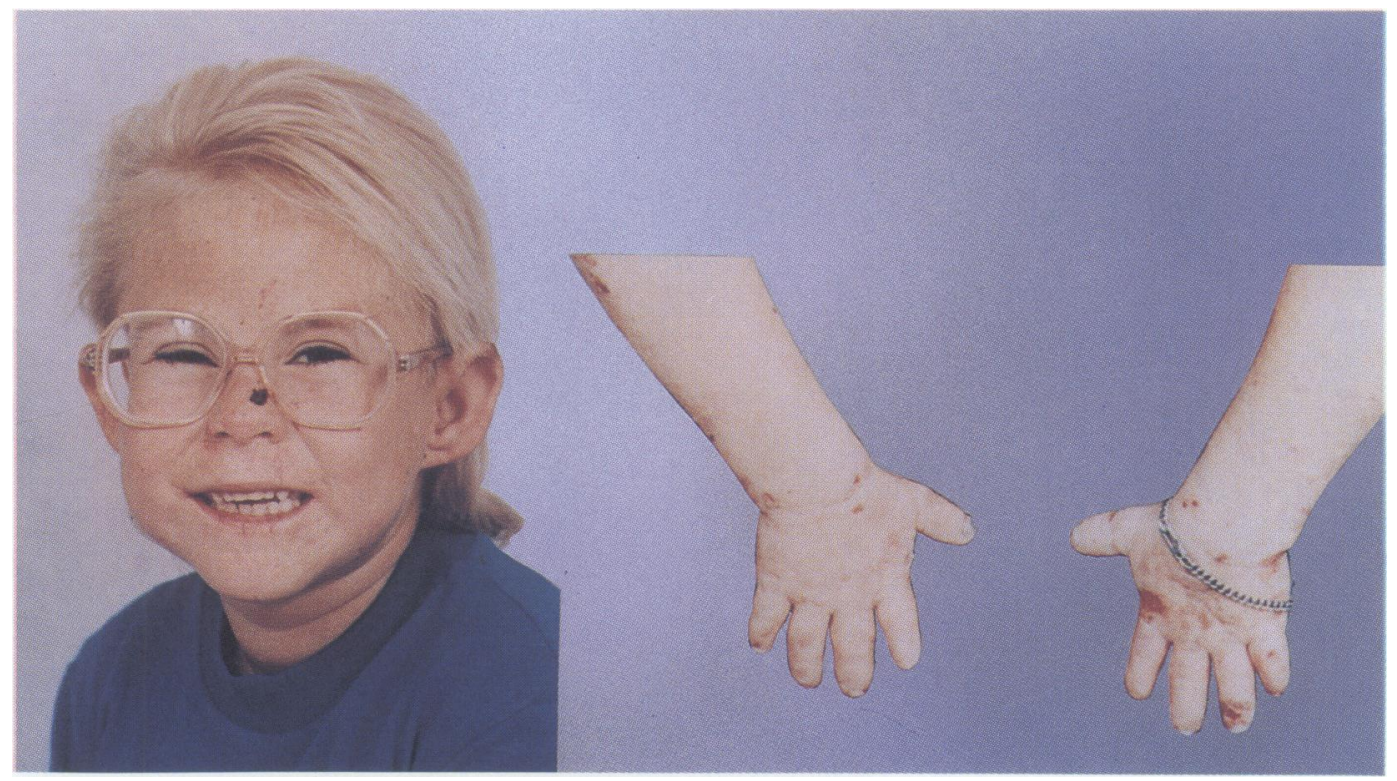

Figure 1 Case 1: mutilating skin changes and brachydactyly are evident.

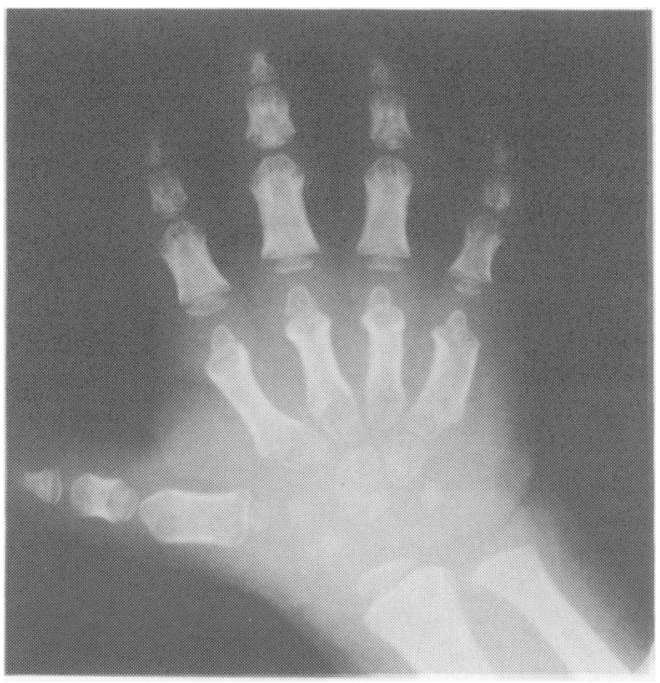

Figure 2 Case 1: marked brachydactylyl depicted on radiograph.

developmental delay, nystagmus and clinodactyly. Skin manifestations were noted from the age of 6 months. He presented to a dermatology clinic at the age of 6 with blistering and fragility of the skin of his hands, face and ears. Examination revealed hypertrichosis, hyperpigmentation, scarring and milia of these areas (Figures 3 and 4). His biochemical profile (Table I) is typical of HVP. This was confirmed by a reduction in PPO activity in Epstein-Barr virus-transformed lymphoblasts to $4.6 \%$ of the control value. His parents were unavailable for testing. No neuropathy was demonstrable and nerve conduction studies in this case were normal.

Topical broad-spectrum photoprotection (titanium dioxide cream), mechanical protection with gloves, and control of secondary infection have reduced the severity and duration of blistering episodes.

\section{Discussion}

The first report of HVP appeared in a letter to the Lancet in $1984^{5}$ and further reports have followed.$^{6-10}$ No case has yet been described in South Africa. We had previously believed that the homozygous state might be lethal. It is probable that HVP, like the heterozygous condition, is subjected to variable expressivity, and that only the less severely affected fetus will survive until birth. It is also possible that some cases of HVP will turn out to be compound heterozygotes rather than true homozygotes when testing at the gene level is possible. It is an interesting observation that all the parents of the cases described thus far appear to have been latent carriers as none are reported to have expressed VP clinically. 


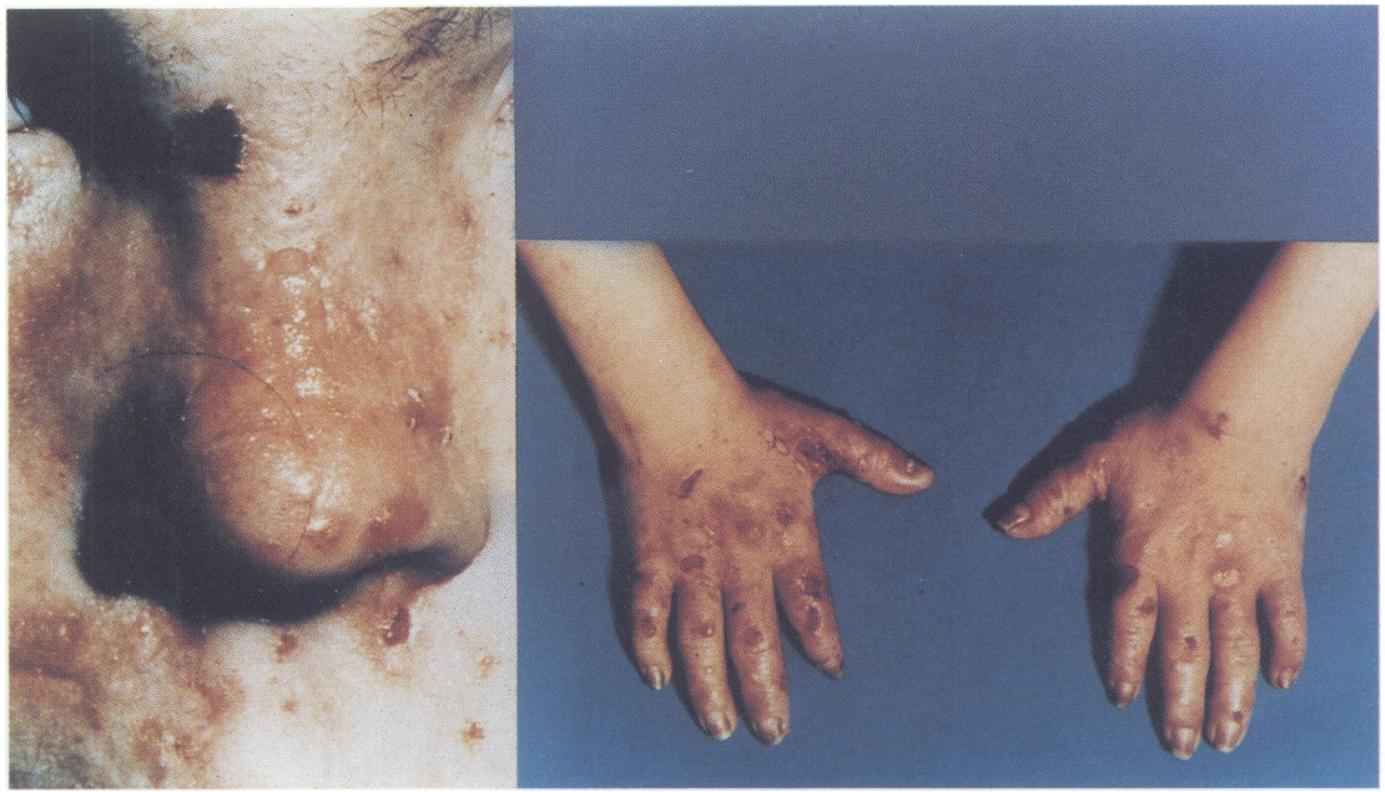

Figure 3 Case 2: similar changes are noted.

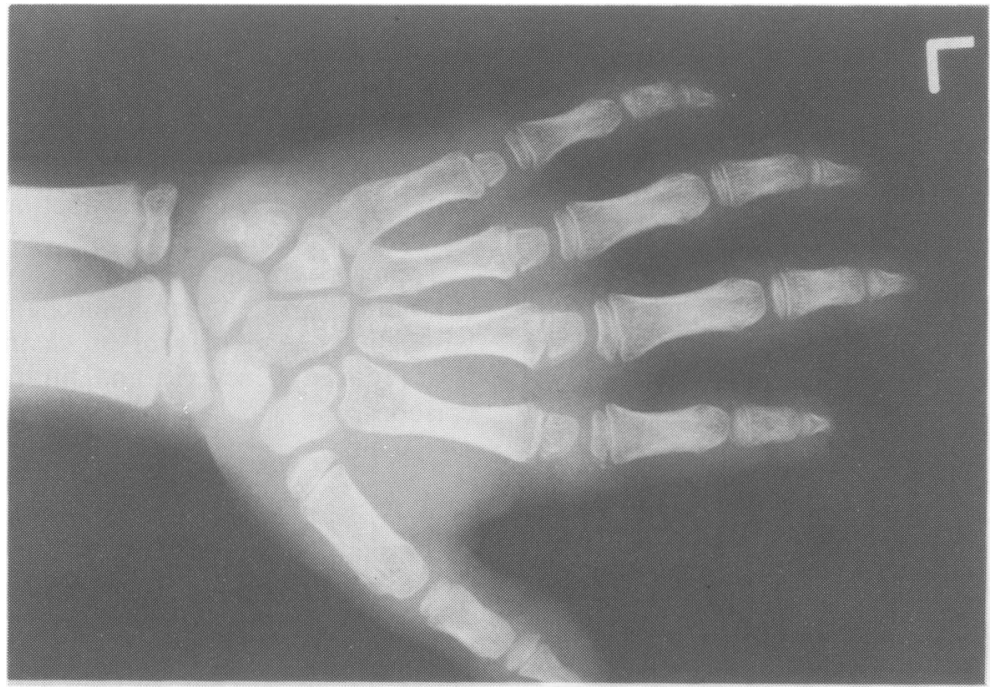

Figure 4 Case 2: similar changes are noted.

A review of the eight reported cases shows them, with one exception, to be remarkably similar (Table II). Both sexes are affected and the condition presents with photosensitivity within days to months of birth. Many have been mentally retarded. Delayed development is common and most will suffer seizures. Nystagmus may be noted. Structural abnormalities of the hands are fre- quently reported, ranging from clinodactyly to $\mathrm{N}_{\mathrm{N}}$ severe deformity. Growth retardation and a retarded bone age are frequent and perhaps invariable.

Reported activities of protoporphyrinogen $\stackrel{\Phi}{\rightarrow}$ oxidase range from 0 to $20 \%$. It is of interest that, 0 with the exception discussed below, none is ${ }_{0}$ reported to have developed elevated porphyrin $\stackrel{\mathbb{\Omega}}{\Omega}$ 


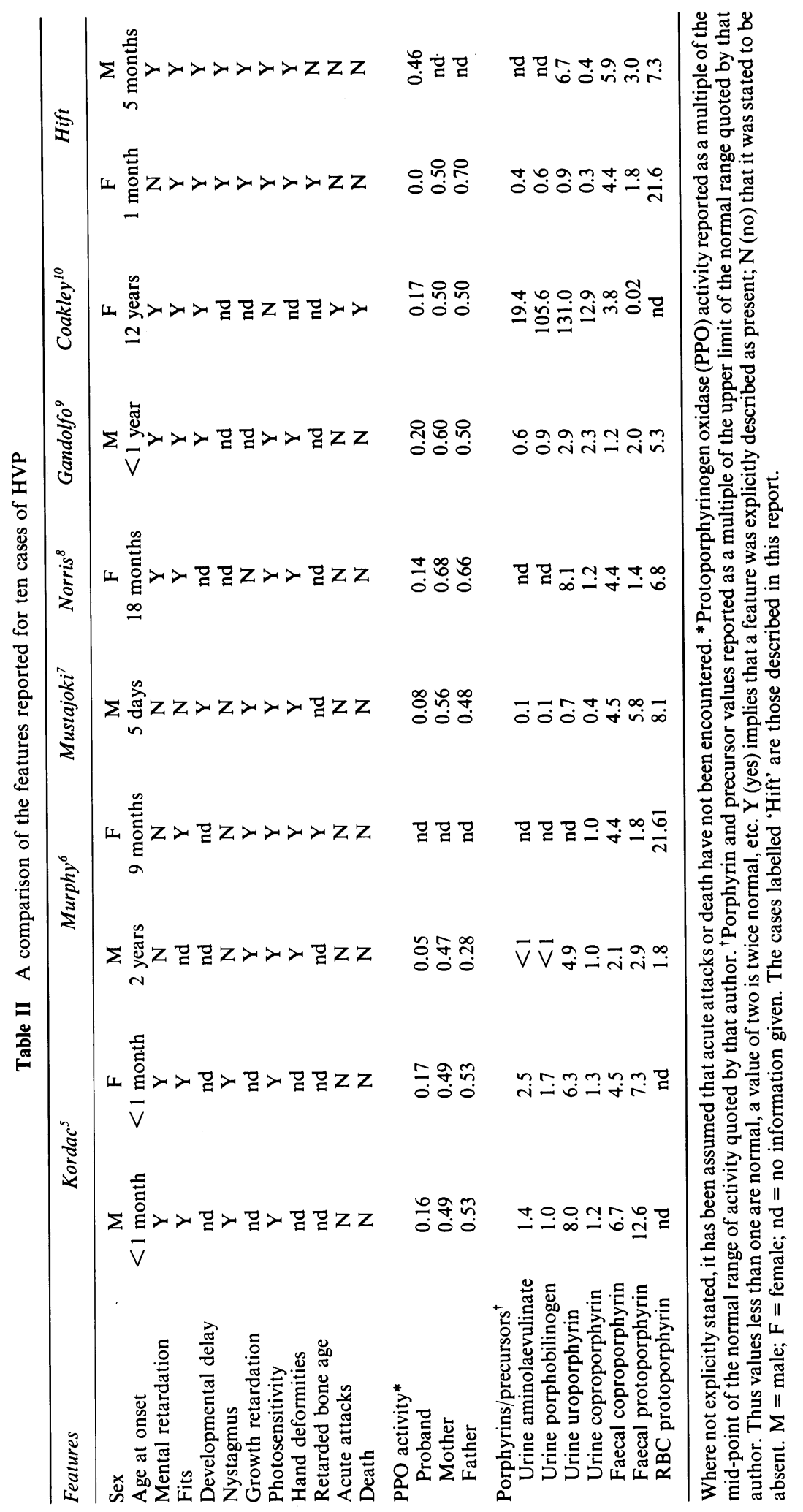


precursor concentrations nor acute attacks, despite the frequency of this complication in heterozygotes who have a much greater PPO activity.

One case, described by Coakley, ${ }^{10}$ is so exceptional that it would appear to constitute, at the very least, a different form of the condition. This child first showed signs of disease at the age of 12 (10 years later than any of the other cases), had no photosensivity, did suffer severe acute attacks and is the only case reported to have died. The biochemical findings are also exceptional; a normal stool protoporphyrin was accompanied by a markedly raised coproporphyrin. In our experience, this is incompatible with VP. Despite the reported deficiency in PPO activity in the proband and parents, therefore, we are not sure that this diagnosis was correct.

To this syndrome we now add two new observations. Clinically manifest involvement of non-sunexposed skin has not yet been reported in VP, though abnormalities on electron microscopy may be shown. It suggests that severe infiltration of the skin, presumably by porphyrins, may be sufficient to evoke cutaneous damage without the mediation of sunlight. Indeed, there is some experimental evidence that porphyrin alone, in the absence of light, may be able to induce the production of collagen by human fibroblasts. ${ }^{11}$ Secondly, a sensory neuropathy of this severity and in the absence of any motor involvement, is unprecedented. In our experience of 300 cases of $\mathrm{VP},{ }^{3}$ neuropathy was limited to those who had suffered obvious acute porphyric attacks and was predominantly a motor neuropathy. We suggest that the severe hand $\frac{6}{5}$ deformities in our first case may be at least in part 2 neuropathic, and similar to the mutilating joint $\frac{3}{8}$ changes seen in congenital sensory neuropathies.

This syndrome raises several questions which are not answerable on the basis of our current understanding of porphyria. We cannot explain howo patients with HVP maintain porphyrin concentra-듬 tions similar to those of the heterozygote in the face $\overline{\overline{\bar{p}}}$ of the near-absence of PPO activity. The $\widetilde{\mathbb{D}}$ pathogenesis of this gross sensory neuropathy in the absence of elevated porphyrin precursors is also ${ }^{\infty}$ unexplained. There is much that remains to be $\vec{\circ}$ learned about the factors influencing the clinical $\overrightarrow{\vec{\omega}}$ expression of these diseases. With a gene frequency ${ }_{\sigma}$ among the Afrikaner community estimated at three per thousand, ${ }^{4}$ homozygous cases should occur 3 with a frequency of 2.25 per million. Thus at leasto seven cases would be expected in this well-defined ${ }_{\infty}^{\infty}$ population, yet this is the only case encountered. $\frac{\infty}{\sigma}$ Further studies, designed to address these questions, are likely to enhance our understanding of $\stackrel{\infty}{\rightarrow}$ the expression and the biochemical and clinicalo features of the more commonly encountered forms of porphyria.

\section{Acknowledgements}

We thank Ms Lavinia Petersen for revising and editix the manuscript, Mr B. Davidson and Ms J. Sutherland for performing the porphyrin estimations on the first case, and Professor G. Elder for determining the PPO activity in the second case.

\section{References}

1. Brenner, D.A. \& Bloomer, J.R. The enzymatic defect in variegate porphyria. $N$ Engl J Med 1980, 302: 765-769.

2. Meissner, P.N., Day, R.S., Moore, M.R., Disler, P.B. \& Harley, E. Protoporphyrinogen oxidase and porphobilinogen deaminase in variegate porphyria. Eur J Clin Invest 1986, 16: 257-261.

3. Eales, L., Day, R.S. \& Blekkenhorst, G.H. The clinical and biochemical features of variegate porphyria: an analysis of 300 cases studied at Groote Schuur Hospital, Cape Town. Int J Biochem 1980, 12: 837-853.

4. Dean, G. \& Barnes, H.D. Porphyria: a South African screening experiment. Br Med J 1958, 1: 298-301.

5. Kordac, V., Deybach, J.C., Martasek, P. et al. Homozygous variegate porphyria. Lancet 1984 , i: 851 .

6. Murphy, G.M., Magnus, I.A., Barrett, D.F. et al. Homozygous variegate porphyria: two similar cases in unrelated families. $J R$ Soc Med 1986, 79: 361-363.

7. Mustajoki, P., Tenhunen, R., Niemi, K.M. et al. Homozygous variegate porphyria: a severe skin disease of infancy. Clin Genet 1987, 32: 300-305.

8. Norris, P.G., Elder, G.H. \& Hawk, J.L.M. Homozygous variegate porphyria: a case report. $B r J$ Dermatol 1990, 122: 253-257.

9. Gandolfo, L.D., Macri, A., Biolcati, G. et al. Homozygous variegate porphyria: revision of a diagnostic error. $\mathrm{Br} J \underline{O}$ Dermatol 1991, 124: 211.

10. Coakley, J., Hawkins, R., Crinis, N. et al. An unusual case of variegate porphyria with possible homozygous inheritance. Aust NZ J Med 1990, 20: 587-589.

11. Varigos, G., Schiltz, J.R. \& Bickers, D.R. Uroporphyrin I stimulation of collagen synthesis in human skin fibroblasts. $J$ Clin Invest 1982, 69: 129-135. 


\section{Corrigendum}

'Homozygous variegate porphyria: an evolving clinical syndrome', by Hift R.J. et al. Postgrad Med $J(1993)$ 69: 781-786. The authors report that they have become aware of some minor errors in the numeric data in Tables I and II. These errors do not in any way alter the conclusions of the paper.

Copies of the revised tables can be obtained from: Dr R.J. Hift, Liver Research Centre, Medical School, University of Cape Town, Observatory 7925, South Africa. 